\title{
O DESCARTE DE MATERIAIS BIBLIOGRÁFICOS NAS BIBLIOTECAS PÚBLICAS GAÚCHAS: Análise do documento de orientação do SEBP/RS
}

\author{
Márcia Carvalho Rodrigues \\ Doutora em Memória e Patrimônio Cultural \\ Professora do Instituto de Ciências Humanas e da Informação \\ Universidade Federal do Rio Grande \\ marciarodriguesfurg@gmail.com
}

Carla Adriane das Neves de Barros

Graduada em Biblioteconomia

Universidade Federal do Rio Grande

Bibliotecária da Biblioteca Rio-Grandense carla.adriane.barros@gmail.com

\begin{abstract}
Resumo
O presente trabalho tece considerações sobre o processo de descarte de materiais bibliográficos no âmbito das bibliotecas públicas do Estado do Rio Grande do Sul. Para tanto, analisa as orientações do Sistema Estadual de Bibliotecas Públicas do Rio Grande do Sul (SEBP/RS). A metodologia adotada se baseia na revisão documental e bibliográfica sobre a temática do descarte, a qual fornece embasamento para a análise. Entendendo, ainda, que os materiais bibliográficos são instrumentos de aquisição de conhecimento, e que mesmo após seu descarte estes seguem tendo valor e importância, realiza-se um levantamento acerca dos possíveis destinos que estes podem receber, para que dessa forma, continuem sendo utilizados, apresentando ideias e sugestões de projetos de incentivo à leitura que já foram postos em prática por diferentes instituições e que fazem uso dos materiais descartados.
\end{abstract}

Palavras-chave

Biblioteca pública. Descarte de materiais bibliográficos. Incentivo à leitura.

\section{INTRODUÇÃO}

O presente estudo buscou evidenciar questões relacionadas ao descarte de materiais bibliográficos, especialmente os livros, nas bibliotecas públicas vinculadas ao Sistema Estadual de Bibliotecas Públicas do Rio Grande do Sul (SEBP/RS). Para tanto, fezse necessário conhecer o documento que regulamenta o processo de descarte nas mesmas. Após contato por e-mail com o $\mathrm{SEBP} / \mathrm{RS}$, o referido documento foi encaminhado às pesquisadoras para realização do estudo. Junto a isso, observou-se, ainda, os destinos dados aos materiais descartados, com a perspectiva de levantar ideias quanto à elaboração de projetos de aproveitamento deste material.
A partir do exposto, esta pesquisa percorreu a problemática do descarte, primeiramente buscando entendimento sobre a importância do estabelecimento de políticas voltadas à remoção de materiais que não servem mais para determinada biblioteca, para fim de orientação padronizada quanto ao seu processo.

Num segundo momento, analisou-se o conteúdo presente no documento de orientação desenvolvido pelo SEBP/RS, a fim de entender o processo sob a perspectiva do sistema que regulamenta o funcionamento das bibliotecas públicas dentro do Estado. Por último, após o entendimento do processo de descarte adotado em âmbito estadual, o trabalho buscou apresentar sugestões de atividades e projetos que pudessem dar aos 
materiais descartados a possibilidade de servir à comunidade, através de ações que incentivem o hábito da leitura naqueles que se sentem, por motivos diversos, distantes do ambiente da biblioteca.

Diante da problemática do descarte e da percepção de que, mesmo descartados, muito livros ainda se encontram em ótimo estado de conservação, o presente estudo norteou-se na busca de respostas ao seguinte questionamento: "Quais as possíveis formas de aproveitar os materiais bibliográficos descartados pelas bibliotecas públicas?”. A partir daí, busca-se compreender como se processa a etapa de descarte de acervo no âmbito das bibliotecas públicas do Estado do RS. Nessa perspectiva, visa especificamente: a) entender a importância do estabelecimento de uma política de descarte para o processo de desenvolvimento da coleção de uma biblioteca; b) analisar, através de revisão literária, o processo de descarte dentro das bibliotecas públicas, além da importância dada a esta etapa; c) investigar as orientações do $\mathrm{SEBP} / \mathrm{RS}$ no que se refere ao descarte de materiais; d) conhecer alternativas de uso e/ou aproveitamento para o material descartado.

Esta pesquisa justificou-se pela preocupação quanto ao destino dado aos materiais descartados pelas bibliotecas públicas do Estado do RS, tendo em vista que muitas vezes a palavra "descarte" soa de forma negativa, sugerindo a ideia de algo que está inutilizado, ou, em outras palavras, está sendo posto fora. Importante destacar, também, que o segundo elemento motivador para a sua realização foi a constatação da escassa bibliografia atualizada existente sobre o tema, especialmente em língua portuguesa, o que evidencia a necessidade de promover mais estudos sobre a temática proposta.

Ao falar no descarte propriamente dito, fica subentendido que esse material não pode ser mais usado, o que nem sempre é verdade. Os livros que as bibliotecas públicas não vão incorporar aos seus acervos poderão servir em projetos de alfabetização e de incentivo à leitura, através de propostas elaboradas pelas próprias bibliotecas, beneficiando, assim, a comunidade que não tem condições de adquirir um livro ou mesmo tempo para frequentar essas instituições. Nesse sentido, o presente trabalho buscou compreender de que forma se processa o descarte nas bibliotecas públicas gaúchas e sugerir alternativas de aproveitamento dos materiais descartados.

A fim de sintetizar o conteúdo apresentado, esclarece incialmente, que o presente artigo compreende, além desta Introdução, uma seção dedicada à compreensão acerca do processo de seleção de materiais, a qual abrange os conceitos de descarte e desbastamento, contextualizando assim todo o processo que culmina na seleção dos materiais que serão descartados. Dentro desta abordagem, realizou-se a análise do documento intitulado "Orientações para o descarte de acervos", elaborado pela SEBP/RS. A seguir apresentam-se, a título de sugestões, cinco projetos que foram idealizados e desenvolvidos por diferentes instituições, em prol do incentivo à leitura, a partir da utilização de materiais descartados por bibliotecas públicas. Por fim, expõem-se as Conclusões desta pesquisa.

\section{BIBLIOTECAS PÚBLICAS: CON- CEITO E CONTEXTO DENTRO DO ESTADO DO RIO GRANDE DO SUL}

Sob o ponto de vista do acesso, toda biblioteca é um local público, uma vez que está aberta ao atendimento de toda comunidade. Por conta disto e da necessidade de entendimento acerca do que se compreende a respeito de biblioteca pública, no âmbito administrativo e mantenedor, faz-se necessário dialogar acerca de seu conceito.

Diante da ambiguidade que o termo "biblioteca pública" carrega, Fernandez, Fernandez e Machado (2016, p. 15) entendem que

[...] é importante compreender que a biblioteca pública é um tipo de instituição cultural, e não é caracterizada pela sua vinculação institucional ou personalidade jurídica. Isso significa que nem todas as bibliotecas públicas são mantidas pelo governo, assim como nem todas as 
bibliotecas mantidas pelo governo são públicas.

De acordo com as autoras, as bibliotecas públicas podem ser divididas segundo diferentes mantenedores:

Dentro do universo das bibliotecas públicas, existem as bibliotecas públicas municipais, estaduais, e federais, e as bibliotecas públicas mantidas pela sociedade em geral, pessoa física ou pessoa jurídica, como as comunitárias. (FERNANDEZ; FERNANDEZ; MACHADO, 2016, p. 15).

Diante de tal aspecto, faz-se necessário ressaltar que o presente trabalho dá ênfase à temática do descarte dentro de bibliotecas mantidas pelo governo estadual do RS, ou seja, entendendo a denominação "biblioteca pública" não apenas no que diz respeito ao acesso de qualquer cidadão a esta, mas sim como está sendo mantida através de verbas públicas.

Contudo, após compreensão acerca da ambiguidade provocada pela denominação "pública", deve-se dar importância ao que tange o conceito de biblioteca como espaço público, de acesso a todo e qualquer indivíduo. Sendo assim, pode-se afirmar que, conforme conceito aceito internacionalmente, a biblioteca pública é considerada hoje como o "[...] centro local de informação, tornando prontamente acessíveis aos seus utilizadores o conhecimento e a informação de todos os gêneros." (CAVALCANTI, 2007, p. 7).

É através das bibliotecas públicas que se tem acesso a uma ampla gama de conhecimentos sem nenhuma restrição, ou seja, sem qualquer distinção a qualquer pessoa. Segundo Correia (2010, p. 10 apud MEDEIROS, 2010, p. 17),

A biblioteca pública, pelas suas características únicas, emerge como um espaço de cidadania, na medida em que se configura um espaço profundamente democrático de fruição da cultura, aberta a todos, independente da condição social e do grupo etário. Quanto mais próxima estiver da comunidade que serve, mais probabilidade terá de cativar todos os seus membros, desde tenra idade e ao longo de toda a vida, sem impor uma ruptura com o contexto familiar. Ao mesmo tempo em que propicia a socialização em torno de práticas culturais mais próximas da cultura erudita, a biblioteca pública pode ainda desempenhar um papel importante no desenvolvimento das competências indispensáveis à plena participação de todos os cidadãos na sociedade.

As bibliotecas públicas têm como objetivo ser espaços socioculturais que disponibilizam acervos sobre os mais variados assuntos, buscando atender às necessidades dos cidadãos, independentemente de sua classe social, religião e/ou raça. Assim, ela caminha na direção contrária à ideia de que estas instituições são locais de estocagem de livros e obras antigas.

Para Antunes, Antunes e Cavalcante (2000, p. 19), biblioteca pública é "[...] o centro de informações da comunidade", pois disponibiliza livros, periódicos, CDs, DVDs, gravuras, fotografias e outros diversos recursos informativos para seu uso, ou, ainda, pode ser definida como

[...] o centro referencial da comunidade, reunindo documentos sobre a sua história, sobre fatos importantes, personagens destacadas, permitindo aos usuários da biblioteca conhecer o município, o seu potencial, as oportunidades de trabalho, de desenvolvimento. (ANTUNES; ANTUNES; CAVALCANTE, 2000, p. 19).

A principal atividade fim de uma biblioteca é o atendimento ao leitor, isto é, fornecer ao usuário as informações às quais ele procura. Nesse sentido, saber repassar a informação com a máxima segurança e objetividade é importante para que o usuário saia da biblioteca com seu objetivo alcançado.

Pensando ainda em tamanha diversidade de cultura existente no território brasi- 
leiro, as bibliotecas públicas enfrentam o desafio de se preparar para atender às necessidades de uma comunidade tão variada. Portanto, cada biblioteca acaba tendo uma identidade única, atendendo cada comunidade e contribuindo para a preservação da história do próprio local. A biblioteca pública pode ser entendida, também, como um lugar de aquisição de conhecimento, de interação do indivíduo com a leitura, e de incentivo a tal prática. Assim, atendendo pessoas de todas as idades e classes sociais.

Uma biblioteca pública é um centro de informações atuando permanentemente, atendendo à demanda da população, estimulando o processo contínuo de descobrimento e produção de novas obras, "organizando a informação para que todo ser humano possa usufruí-la". (MILANESI, 1986, p. 15, grifo do autor).

De modo sucinto e com outras palavras, uma biblioteca pública é um lugar de compartilhamento de ideias e produção de novas obras, aberta ao público de um modo geral.

\subsection{Breve histórico da Biblioteca Pública do Estado do Rio Grande do Sul}

A primeira biblioteca pública mantida pelo Estado do RS começa, ainda, nos tempos da Província de São Pedro, durante o reinado de D. Pedro II. O então deputado João Pereira da Silva Borges Filho, no dia 30 de março de 1871, apresentou à Assembleia Provincial um projeto de lei pedindo a criação de uma biblioteca oficial, o qual foi aprovado e transformado na Lei n. 724, de 14 de abril de 1871, sendo sancionado pelo presidente da Província Francisco Xavier Pinto de Lima (BIBLIOTECA PÚBLICA DO ESTADO DO RIO GRANDE DO SUL, 2016).

A Biblioteca Pública do Estado (BPE) foi aberta ao público em 1877, com cerca de 1.800 obras (aproximadamente 3.500 volumes); recebeu 1.483 usuários que consultaram 691 obras, no ano de 1877, tendo sido seu diretor e organizador o Dr. Fausto de Freitas e Castro. Já em 1906, sob influência do positivismo, a Biblioteca passou a incorporar administrativamente o Arquivo Público. Foi nesse ano também que o poeta Vitor Silva, nomeado diretor, começou a implantar novos atributos para a biblioteca, sendo uma delas a Classificação Decimal Universal (CDU). (BIBLIOTECA PÚBLICA DO ESTADO DO RIO GRANDE DO SUL, 2016).

A construção da primeira parte do prédio da BPE começou no ano de 1912. Em 1915, foi transferida, como instituição autônoma, para a Rua Riachuelo, esquina com General Câmara. O prédio, inaugurado em 7 de setembro de 1922, fez parte das comemorações ao centenário da Independência do Brasil. (RIO GRANDE DO SUL. Secretaria da Cultura, 2017).

Em 1986, o prédio da biblioteca foi tombado pelo Instituto do Patrimônio Histórico e Artístico do Estado (IPHAE), e em 2000 pelo Instituto Patrimônio Histórico e Artístico Nacional (IPHAN). Já no ano de 1996, a Biblioteca foi informatizada, foi criado um Setor de Multimeios, oferecendo acesso gratuito a Internet, e-mail, vídeos e CD-ROM, bem como um Setor de Obras em Braile. (RIO GRANDE DO SUL. Secretaria da Cultura, 2017).

\subsection{O Sistema Estadual de Bibliotecas Públicas do Estado do Rio Grande do Sul - SEBP/RS}

Estruturado em 1977, porém instituído pelo Decreto n. 30.947, de 24 de dezembro de 1961, o SEBP/RS tem como objetivo a organização, o apoio, a coordenação e o planejamento das bibliotecas públicas do RS. O Sistema disponibiliza acervo aos municípios que tenham bibliotecas públicas cadastradas e ativas, oferecendo, a cada dois meses, materiais e treinamentos em softwares especializados na gestão e organização de acervos. Conta, atualmente, com 532 bibliotecas cadastradas em sua base de dados. (RIO GRANDE DO SUL. Sistema Estadual de Bibliotecas Públicas, 2017).

As bibliotecas novas são acompanhadas pelo SEBP/RS, recebendo orientações e treinamento acerca dos procedimen- 
tos recomendados pelas técnicas em uso e prescrições elaboradas pela Organização das Nações Unidas para a Educação, a Ciência e a Cultura (UNESCO). Esse suporte vai além da organização, havendo ainda incentivo para o aumento da capacidade das mesmas, através da contratação de bibliotecários, ofertando um serviço de melhor qualidade, acervo adequado e estabelecimento de relações de cooperação com a comunidade e com outras instituições governamentais e não governamentais. (RIO GRANDE DO SUL. Sistema Estadual de Bibliotecas Públicas, 2017).

\section{SELEÇÃO DE MATERIAIS PARA AQUISIÇÃO: O CASO DAS DOAÇÕES}

A diversificação do acervo de uma biblioteca pública visa atender aos anseios da comunidade, que por conta de sua aquisição cognitiva diária, acaba criando novas demandas. Para Carvalho e Klaes (1979 apud ROMANI; BORSZCS, 2006, p. 24), o desenvolvimento de coleções

[...] é o conjunto de atividades caracterizadas por um processo decisório que determina a conveniência de se adquirir, manter ou descartar materiais, tendo como base critérios previamente definidos, que, por sua vez, são definidos por meio das diretrizes estabelecidas para formação ideal de um acervo, visando manter um conjunto de documentos (material bibliográfico e especial), que atenda às necessidades de informação dos clientes e aos objetivos da instituição [...].

Sendo assim, o desenvolvimento de coleções abrange o estudo e o planejamento dirigidos à aquisição e ao descarte de materiais, respeitando critérios pré-estabelecidos, que visam atender às demandas dos diferentes grupos existentes na sociedade.

Observa-se, então, que o acervo deve ser bem planejado e pode ser constituído tanto por materiais adquiridos através de compras, quanto por doações feitas pela própria comunidade. Tais doações, grande parte das vezes, chegam até a biblioteca sem qualquer manutenção e observação quanto à sua utilidade para o acervo. Segundo Barbosa (1985), as doações precisam passar por uma criteriosa análise antes de serem incorporadas ao acervo.

\begin{abstract}
As doações são de extrema importância para o desenvolvimento da coleção, porque muitas ofertas são excelentes; no entanto, devem ser estabelecidos critérios para o seu tratamento. A biblioteca deve aceitar todas as doações de livros, revistas ou de qualquer outro material, mas sua incorporação à coleção não deve ser indiscriminada; somente serão incorporados ao acervo os documentos que forem julgados úteis, sendo observados os critérios já existentes para a seleção. Deve ficar claro que a biblioteca se reserva o direito de dispor do material oferecido pela forma que lhe pareça conveniente. (BARBOSA, 1985, p. 56).
\end{abstract}

As doações passam por uma avaliação, na qual são observados, dentre outros, os seguintes aspectos: o estado de conservação do livro em si (se ele não está rasgado, mofado ou apresentando outro tipo de contaminação biológica, rabiscado ou com falta de páginas); atualidade do tema: os assuntos tratados estão atualizados ou não, e se esse livro contém temas relevantes para a biblioteca ou para a comunidade a qual atende; quando já consta no acervo outro exemplar do mesmo título analisa-se, também, o histórico de utilização desta obra, ou seja, quantas vezes ela foi solicitada pelos usuários, para definir a quantidade de exemplares que necessitam ficar à disposição da comunidade, conforme política da instituição.

Após passar por avaliação, os livros doados serão incorporados ou não ao acervo. Os que irão permanecer, deverão passar por higienização, processamento técnico e preparo para circulação, até estarem disponíveis aos usuários, enquanto os demais poderão ser descartados, doados para outras bibliotecas ou, ainda, utilizados em projetos de incentivo à leitura. 


\subsection{Descarte e desbaste}

Inicialmente, é preciso diferenciar os conceitos de descarte e desbaste, para que a decisão correta seja tomada ao realizar um destes procedimentos em uma biblioteca. $\mathrm{O}$ descarte é uma etapa, dentro da política de desenvolvimento de coleções, e é consequência da avaliação de coleções. Tanto a seleção quanto o descarte são etapas dessa política.

Maciel e Mendonça (2006) classificam o descarte como a retirada do material do acervo da biblioteca, com a correspondente baixa nos arquivos de registro do mesmo. Já o desbaste ou desbastamento, consiste na retirada de documentos pouco utilizados pelos usuários, de uma coleção de uso frequente para outros locais, os quais podem ser depósitos especialmente criados para abrigar este material, para consultas eventuais. Maciel e Mendonça (2006) explicam, ainda, que o desbastamento pode vir a melhorar a qualidade do acervo, uma vez que o espaço seria otimizado, sendo aproveitado para a disposição de novas obras.

Para Alonso (1988), a definição de um roteiro de descarte deve ter como objetivo principal a manutenção do acervo da biblioteca, com o nível de adequação requerido para o melhor atendimento aos usuários, cobrindo todos os campos de assuntos definidos como pertinentes, dentro das diretrizes políticas e das atividades da instituição à qual se vincula.

Nesse sentido, destacamos algumas diretrizes para a atividade de descarte, conforme Alonso (1988):

a) os envolvidos na tarefa devem ter experiência profissional e estar seguros de que descartar é uma atividade intelectual e operacional determinante para o desenvolvimento da coleção;

b) deve-se ter conhecimento da área que está sendo avaliada;

c) necessita-se detectar quem usa os materiais, como estes são usados e, principalmente, porque deixaram de ser usados; d) a ocasião mais indicada para o descarte é, aparentemente, durante o inventário da coleção.

Evans (1979 apud SILVA; CASTRO FILHO; QUIRINO, 2012) define o desbastamento como uma prática de transferência do acervo por conta do excesso de exemplares ou por sua pouca utilização durante muito tempo. Além disso, o autor considera a existência de três aspectos importantes para o desbastamento, sendo eles: a) conservar o espaço; b) melhorar o acesso e; c) reduzir gastos. Segundo o autor, algumas desculpas frequentes por parte dos bibliotecários para não realizar o desbastamento são: "[...] falta de tempo, medo de errar, colocar fora do acervo e relutância para jogar um livro fora.". (EVANS, 1979 apud SILVA; CASTRO FILHO; QUIRINO, 2012, p. 56).

Segundo Rogers (2007 apud SILVA; CASTRO FILHO; QUIRINO, 2012), O descarte tem uma função útil nas bibliotecas, porém tem sido negligenciada:

O descarte ou o remanejamento se referem à remoção de materiais desatualizados, obsoletos e desgastados, estas atividades são tão importantes quanto a aquisição. A coleção da biblioteca se torna atualizada e renovada quando o remanejamento é feito. (ROGERS, 2007 apud SILVA; CASTRO FILHO; QUIRINO, 2012, p. 59).

Interessante a observação de Vergueiro (1987, p. 22, grifo do autor), quando considera que

Sob certos aspectos, é uma temeridade afirmar-se que a preocupação com uma seleção mais cuidadosa dos materiais a serem incorporados ao acervo surgiu na década de 60 ou 70. Esta preocupação parece sempre ter existido, mas localizavase muito mais no acréscimo de novos títulos à coleção, no sentido da "construção" [...].

Percebe-se, através de sua fala, a atualidade deste assunto, apesar do seu texto ter sido publicado há três décadas, o que 
corrobora com a afirmação realizada na Introdução deste trabalho, quando as autoras comentaram a escassez de publicações em idioma português, atuais, sobre o tema em questão.

\section{2 "Orientações para o descarte de acer- vos": análise do documento}

O documento "Orientações para o descarte de acervos", elaborado pelo SEBP/RS e disponibilizado às bibliotecas públicas do Estado, traz orientações sobre como proceder ao descarte de livros. Tal serviço, como observado na revisão de literatura, é de suma importância dentro de uma biblioteca, uma vez que busca a manutenção de uma coleção de qualidade e que seja realmente utilizada pelo seu público. Cabe, aqui, lembrar a fala de Maciel e Mendonça (2006), quando explicam que o descarte é uma forma de atualizar o acervo, abrindo espaço para novas obras, fazendo com que a biblioteca se atualize.

Os processos de análise e descarte dos livros devem ser feitos de forma cuidadosa e crítica, de maneira que não sejam executados de modo improvisado ou subjetivo, respeitando assim os critérios já descritos neste estudo, sobre o estado de conservação e a utilidade dos materiais selecionados. O documento "Orientações" traz as razões pelas quais esta tarefa deve ser executada:

a) conteúdo do material (desatualizado ou de pouco interesse);

b) condições físicas do material (deteriorado, rasgado, sem folhas, encadernação irreparável, etc.);

c) padrões de uso (material pouco ou nunca utilizado, de interesse limitado);

d) material que possa ser enviado para outro local de armazenamento, cujo custo de manutenção seria melhor, sem prejuízo do atendimento da biblioteca;

\footnotetext{
${ }^{1}$ Daqui em diante será utilizado o título encurtado "Orientações" para representar o documento "Orientações para o descarte de acervos", do SEBP/RS.
}

e) necessidade de melhorar o uso dos recursos da biblioteca e ampliar o espaço entre as estantes. Assim, os leitores podem andar com mais conforto e espaço entre as estantes, encontrando mais facilmente os livros que desejam. O aspecto visual da biblioteca também melhora. (RIO GRANDE DO SUL. Sistema Estadual de Bibliotecas Públicas, [200-])

Quanto a isso, Duranti (2014) salienta que o processo de descarte deve respeitar cinco critérios básicos, sendo estes: de uso, de qualidade, de redundância, de disponibilidade e de condições físicas. Dessa forma, deve-se fazer a retirada deste material através de uma análise que respeite os critérios citados, analisando ainda as consequências que isso pode trazer para os usuários.

Outro aspecto citado nas "Orientações" e de suma importância para a organização e controle de obras é o registro do descarte, assim como é feito na hora em que se incorpora uma nova obra ao acervo da biblioteca. Deste modo, é possível manter na base de dados um controle de edições anteriores de livros que já passaram pelo acervo, por exemplo, bem como acompanhar a sua "vida útil" dentro da instituição.

As "Orientações" enfatizam, também, a necessidade de relacionar as obras descartadas através do registro em atas, podendo ser feita apenas a relação pelo número de registro das obras descartadas, para facilitar e garantir que esse processo seja feito por uma equipe multidisciplinar, chamando profissionais das respectivas áreas para colaborar nesse processo, validando o descarte e permitindo que essa tarefa seja feita de maneira a não causar prejuízo aos leitores.

O documento também passa instruções sobre como organizar o descarte, entendendo que, para que tal procedimento seja feito de forma satisfatória, o mesmo deve levar em conta alguns aspectos, tais como, o perfil de usuários da biblioteca, os objetivos da mesma, a idade e o tipo da coleção, o espaço físico e a equipe disponíveis na biblioteca. Em acréscimo, Alonso (1988) afirma que o objetivo principal do descarte é 
a manutenção da biblioteca de forma adequada às necessidades dos seus usuários.

Dentre as orientações existentes, pode-se citar aspectos sobre a periodicidade de seleção de material para descarte, modo como isto deve ser executado e consistência quanto aos critérios utilizados para tal seleção. No que tange à questão da periodicidade, o documento instrui à análise do acervo periodicamente, a fim de retirar das estantes aquelas obras que já não apresentam utilidade para seus usuários, ou que estão em grave estado de deterioração. Nas palavras de Weitzel (2006), faz-se necessário uma avaliação periódica a fim de adequar as bibliotecas às demandas que surgem com o passar dos tempos.

As "Orientações" indicam que a biblioteca deve se dedicar, ao menos uma vez por ano, à revisão da coleção, usando, em média, uma semana para cada área do conhecimento, se a biblioteca for grande. Já em bibliotecas menores, a revisão da coleção deve ser constante para que não perca qualidade. Para tanto, uma equipe multidisciplinar deve fazer uma relação dos títulos que estão desatualizados e sem uso. Uma boa ocasião para realizar a seleção de obras para descarte é durante o processo de inventário, sempre tendo cuidado para não retirar títulos do acervo que acarretem prejuízo aos usuários. O documento de "Orientações" não estipula prazos, só indica que essa revisão deve ser periódica. Acreditamos que a periodicidade da avaliação dependerá do tamanho da biblioteca e da quantidade de pessoal qualificado disponível para realização de tal atividade.

Quanto à multidisciplinaridade, Figueiredo (1985) sugere que vários membros da biblioteca examinem cada porção da coleção a fim de conhecer a importância para sua comunidade, sabendo que é preciso ouvir especialistas para se chegar um consenso. Dentre as categorias de obras passíveis de descarte, as mais comuns, segundo as "Orientações", são:

a) títulos duplicados, sendo que após seleção dos excedentes, deverão permanecer no acervo pelo menos dois exemplares;

b) edições desatualizadas, que acabaram sendo substituídas por edições mais recentes;

c) materiais desgastados: sujos, rasgados, em mau estado de conservação, incompletos;

d) livros que nunca foram usados ou que estão sem uso há pelo menos cinco anos.

O documento do SEBP/RS sugere, ainda, que cada área tenha seus próprios critérios para o descarte, e fornece o passoa-passo para a execução deste procedimento para: Obras gerais de referência; Religião e Filosofia; Ciências Sociais; Filologia e Linguística; Ciências e Tecnologia; Arte, Música, hobbies etc.; Literatura; História; Geografia; Biografias.

Entendendo a biblioteca como um organismo em constante crescimento, as "Orientações" visam a auxiliar a manutenção de acervos que satisfaçam as necessidades dos usuários, preocupando-se com a sua efetividade, evitando que as mesmas se transformem em depósitos de livros sem utilidade.

Sendo assim, a ideia presente em tais orientações é de mostrar a importância da manutenção de um acervo de livros atualizados, para que assim o leitor usufrua de um material condizente como a realidade e com os padrões ofertados no contexto atual. Ao analisar o documento e confrontá-lo com os teóricos apresentados na revisão de literatura, percebe-se que há consenso entre as partes, evidenciando a realização de pesquisa para sua elaboração. O documento aponta como possíveis destinos a serem dados aos materiais descartados os seguintes:

a) que sejam doados a outra instituição;

b) que sejam encaminhados para a reciclagem;

c) que sejam vendidos a peso, caso a prefeitura responsável permita. 
Assim, entendemos que os materiais descartados possam receber outro tratamento, desde que em bom estado de conservação. Neste sentido, a seção a seguir exemplifica, através de projetos desenvolvidos por diferentes instituições brasileiras, alternativas distintas de tratar o material descartado.

\section{EXEMPLOS DE PROJETOS DE IN- CENTIVO À LEITURA QUE FAZEM USO DE MATERIAIS DESCARTADOS}

Conforme mencionado anteriormente, este trabalho teve como um de seus objetivos pesquisar atividades de incentivo à leitura que dessem nova oportunidade de uso aos materiais descartados. Trazemos como exemplos, cinco projetos com repercussão positiva que se enquadraram na pesquisa. Inicialmente, buscou-se projetos desenvolvidos em âmbito estadual, porém, na falta destes, ampliou-se o leque de busca para o âmbito nacional.

\subsection{Pegaí - Leitura Grátis}

Situado na cidade de Ponta Grossa, no Paraná (PR), o projeto "Pegaí - Leitura Grátis" foi criado em 2013, a partir de uma iniciativa sem fins lucrativos. Tem como objetivo o incentivo ao hábito de leitura, recebendo doações de livros que são separados e registrados, classificados de acordo com a faixa etária, e posteriormente são disponibilizados em estantes. A população pode retirar os livros para leitura, sem necessitar fazer qualquer cadastro, havendo apenas a exigência de que os mesmos, após serem lidos, sejam devolvidos em algum ponto de coleta. (PROJETO PEGAI LEITURA GRÁTIS, 2017).

O projeto conta com um acervo de livros do gênero literário, tais como: poesias, soneto, crônicas, gibis e outros. Quanto às doações, não são aceitos livros técnicos, religiosos, lista telefônica, apostila, revistas, dicionários, enciclopédias. O projeto conta ainda com o apoio de mais de 70 voluntários e cerca de 45 empresas e entidades dos mais diversos setores. (PROJETO PEGAÍ LEITURA GRÁTIS, 2017).

\subsection{Projetos da Biblioteca Pública Muni- cipal Josué Guimarães}

A Biblioteca Pública Municipal Josué Guimarães, situada em Porto Alegre, conta com dois projetos que fazem uso dos descartes que ocorrem na instituição, sendo estes o "Projeto Descarte" e a "Feira de Troca de Livros".

O "Projeto Descarte" visa à circulação dos livros, colocando o acervo descartado ou excedente em outras bibliotecas, contribuindo assim para a criação de bibliotecas comunitárias na cidade, assim como a manutenção de outras, como bibliotecas de escolas públicas e de instituições prisionais. $\mathrm{O}$ projeto atende, ainda, à comunidade na medida em que se criam destinos adequados a estas publicações.

Atuando também em prol do incentivo à leitura, a "Feira de Troca de Livros" funciona de modo a interagir com outras bibliotecas, compartilhando saberes e experiências, e incentivando o interesse pelos livros e pela leitura. Neste evento, as pessoas podem trocar livros já lidos por outros que estão disponíveis, em forma de escambo. (BIBLIOTECA PÚBLICA MUNICIPAL JOSUÉ GUIMARÃES, 2017).

\subsection{Descarte Legal de Obras Bibliográfi- cas}

Criado em 2015, pela Biblioteca Pública Municipal de Madeira de Freitas, em Cariacica, cidade do Estado do Espírito Santo, o projeto disponibiliza as obras descartadas por um período de seis meses, na modalidade "pegue e leve". Ficam as obras em local de fácil acesso, ao alcance de todos. $\mathrm{O}$ descarte das obras ocorre uma vez por ano, por conta de uma Comissão Permanente de Descarte de Obras Bibliográficas, que avalia as obras e publica um edital informando quais serão retiradas do acervo. (DESCARTE LEGAL..., 2017).

\subsection{Banco do Livro}

Através da Biblioteca Pública Municipal Dr. Nilo Peçanha, a Prefeitura de Biri- 
gui, município paulista, criou por meio da Lei n. 6.029/2015, o "Banco do Livro". A lei regulamenta e oficializa as doações para a redistribuição e o descarte de obras inutilizadas. A partir deste projeto, livros doados pela comunidade são selecionados e redistribuídos para bibliotecas escolares, organizações não-governamentais e associações sem fins lucrativos. (BIRIGUI, 2017).

\subsection{Freguesia do Livro}

A "Freguesia do Livro" é uma organização sediada em Curitiba/PR, que desde 2012 promove leitura, levando livros ao encontro dos leitores. A iniciativa propõe uma corrente literária que coloca em movimento livros que estavam parados nas casas de pessoas, incentivando a leitura para todos em todos os lugares. (FREGUESIA DO LIVRO, 2017).

\section{CONCLUSÕES}

Ao longo deste artigo, buscou-se refletir acerca do importante papel das bibliotecas públicas para a sociedade, como espaço de aquisição e construção de saberes, disponibilizando um número considerável de obras, com a finalidade de atender aos mais diversos grupos sociais.

Buscou-se, também, entender os princípios que orientam o desenvolvimento de coleções e o processo de descarte, que se fazem necessários para a atualização e modernização das bibliotecas, acompanhando as mudanças que a sociedade vem enfrentando.

A etapa da revisão de literatura sobre o tema em questão enfrentou algumas dificuldades no que tange à identificação de textos mais atuais, o que nos leva a concluir que tal temática não tem sido objeto de debate de estudos recentes.

Além da construção teórica elaborada a partir de textos publicados, o artigo contou, ainda, com a análise do documento "Orientações para o descarte de acervos", direcionado às bibliotecas públicas do Estado do RS.

Após a construção de entendimento sobre as bibliotecas públicas, o SEBP/RS e o descarte de acervos, buscou-se soluções para este último aspecto, evidenciando as possibilidades de utilização dos materiais descartados. A partir da apresentação dos projetos citados, foi possível perceber que existem diversas possibilidades de aproveitamento destes materiais descartados, havendo assim a chance de fazer com que estes se tornem fontes de inspiração e incentivo à leitura por parte de toda a comunidade, principalmente no Estado do RS, uma vez que este conta com diversas bibliotecas públicas e raros registros de projetos desta natureza.

A partir do exposto, entende-se que o trabalho apresenta questões relevantes, buscando soluções para uma problemática cotidiana das bibliotecas públicas, visando ao aproveitamento dos materiais descartados e a promoção de projetos que aproximem a informação do leitor.

\title{
THE DISCARDING OF BIBLIOGRAPHIC MATERIALS IN PUBLIC LIBRARIES IN RIO GRANDE DO SUL (BRAZIL): Analysis of the SEBP/RS Guidance Document
}

\begin{abstract}
The present work deals with the process of discarding bibliographical materials within the public libraries of the State of Rio Grande do Sul. For this purpose, it analyzes the guidelines of the State Public Library System of Rio Grande do Sul (SEBP/RS). The methodology adopted is based on the documentary and bibliographic review on the discarding theme, which provides basis for the analysis. Understanding, also, that the bibliographic materials are instruments of knowledge acquisition, and that even after their disposal these continue having value and importance, a survey is made on the possible destinations that these can receive, so that they continue to be used, presenting ideas and suggestions of projects to encourage reading that have already been put into practice by different institutions and that make use of discarded materials.
\end{abstract}

Keywords

Public library. Discard of bibliographic materials. Encouraging reading. 
Artigo recebido em 22/04/2018 e aceito para publicação em 24/06/2018

\section{REFERÊNCIAS}

ALONSO, M. D. L. Descarte. Revista de

Biblioteconomia de Brasília, v. 16, n. 2, p. 191-206, jun./dez. 1988.

ANTUNES, M. C.; ANTUNES, W. A.; CAVALCANTE, G.A. Curso de capacitação para dinamização e uso da biblioteca pública: manual. São Paulo: Global, 2000.

BARBOSA, J. P. Políticas de seleção em bibliotecas públicas: uma questão prioritária. Cadernos de Biblioteconomia, Recife, n. 9, p. 49-60, dez. 1985.

BIBLIOTECA PÚBLICA DO ESTADO DO RIO GRANDE DO SUL. Histórico da Biblioteca. Porto Alegre, [2016]. Disponível em: <https://goo.gl/P5Pz>. Acesso em: 23 set. 2017.

BIBLIOTECA PÚBLICA MUNICIPAL JOSUÉ GUIMARÃES. Projetos. Porto Alegre, 2017. Disponivel em:

$<$ https://goo.gl/eA77Q4>. Acesso em: 23 set. 2017.

BIRIGUI. Projeto Banco do Livro. Birigui, 2017. Disponível em:

<https://goo.gl/kDS1ri>. Acesso em: 23 set. 2017.

CAVALCANTI, I. G. M. Políticas públicas de bibliotecas públicas: o caso do SNBP. In: SEMINÁRIO DE BIBLIOTECAS, 10., 2007, Campinas. [Resumos...]. Rio de Janeiro: [s.n.], 2007. Disponível em:

$<$ https://goo.gl/dS8MNu>. Acesso em: 12 ago. 2017.

DESCARTE LEGAL DE OBRAS BIBLIOGRÁFICAS. Cariacica, 2017. Disponível em: <https://goo.gl/L8kkTq>. Acesso em: 23 set. 2017.

DURANTI, B. Evaluación de colecciones en una biblioteca acadêmica: aplicación de los métodos de Slote y Mcclellan en rela- ción al expurgo. 2014. Monografia (Licenciada em Bibliotecología y Ciencia de la Información) - Universidad Nacional de la Plata, 2014.

FERNANDEZ, C.; FERNANDEZ, M. A. A; MACHADO, E. Bibliotecas públicas: um equipamento cultural para o desenvolvimento local. Recife: Centro de Desenvolvimento e Cidadania, 2016.

FIGUEIREDO, N. M. Metodologias para avaliações de coleções incluindo procedimento para revisão, descarte e armazenamento. Brasília: IBICT, 1985.

FREGUESIA DO LIVRO. Curitiba, 2017. Disponível: <https://goo.gl/OX1RtV>. Acesso em: 02 nov. 2017.

MACIEL, A. C.; MENDONÇA, M. A. R. Bibliotecas como organizações. Rio de Janeiro: Interciencia; Niterói: Intertexto, 2006.

MEDEIROS, A. L. S. Biblioteca e cidadania. Sinais sociais, Rio de Janeiro, v. 4, n. 13, p. 10-45, maio/ago. 2010. Disponível em: <https://goo.gl/ShUZ5Z>. Acesso em: 12 ago. 2017.

MILANESI, L. Ordenar para desordenar: centros de cultura e bibliotecas públicas. São Paulo: Brasiliense, 1986.

PROJETO PEGAÍ LEITURA GRÁTIS. Ponta Grossa, 2017. Disponível em: <https://goo.gl/v3UWzQ>. Acesso em: 23 set. 2017.

RIO GRANDE DO SUL. Secretaria da Cultura. Sistema Estadual de Bibliotecas. Porto Alegre, [2017]. Disponível em: $<$ https://goo.gl/nkmmLi>. Acesso em: 23 set. 2017.

RIO GRANDE DO SUL. Sistema Estadual de Bibliotecas Públicas. Lista de Bibliotecas do RS. Porto Alegre, [2017]. Disponível 
em: < https://goo.gl/ysKfdf>. Acesso em: 23 set 2017 .

Orientações para o descarte de acervos. Porto Alegre: [200-].

ROMANI, C.; BORSZCZ, I. (Org). Unidades de informação: conceitos e competências. Florianópolis: UFSC, 2006.

SILVA, M. R.; CASTRO FILHO, C. M.; QUIRINO, P. O. Desbaste e descarte em bibliotecas universitárias: mapeamento da produção científica. Brazilian Journal of
Information Science: BJIS, Marília, v. 6, n. 2, p. 49-64, jul./dez. 2012. Disponível em: $<$ https://goo.gl/C9nTnw>. Acesso em: 23 set. 2017.

VERGUEIRO, V. C. S. Estabelecimento de políticas para o desenvolvimento de coleções. Revista de Biblioteconomia de Brasília, v. 15, n. 2, p. 193, 1987.

WEITZEL, S. R. Elaboração de uma política de desenvolvimento de coleções em bibliotecas universitárias. Rio de Janeiro: Interciência, 2006. 